Hum. Reprod. Advance Access published October 12, 2016

Human Reproduction, pp. I-I 3, 2016

doi:10.1093/humrep/dew246

human

reproduction

ORIGINAL ARTICLE Andrology

\title{
Semen quality impairment is associated with sexual dysfunction according to its severity
}

\author{
F. Lotti ${ }^{1, \dagger}$, G. Corona ${ }^{1,2, \dagger}$, G. Castellini' , E. Maseroli', M.G. Fino', \\ M. Cozzolino ${ }^{3}$, and M. Maggi ${ }^{1,4, *}$
}

'Sexual Medicine and Andrology Unit, Department of Experimental and Clinical Biomedical Sciences, University of Florence, Florence, Italy ${ }^{2}$ Endocrinology Unit, Maggiore-Bellaria Hospital, Bologna, Italy ${ }^{3}$ Division of Obstetrics and Gynecology, Department of Experimental and Clinical Biomedical Sciences, University of Florence, Florence, Italy ${ }^{4}$ I.N.B.B. - Istituto Nazionale Biostrutture e Biosistemi, 00136 Rome, Italy

*Correspondence address. Sexual Medicine and Andrology Unit, Department of Experimental and Clinical Biomedical Sciences, University of Florence, Viale Pieraccini 6, 50।39, Florence, Italy. Tel: +39-55-427।415; Fax: +39-55-427|4|3; E-mail: m.maggi@dfc.unifi.it

Submitted on April 15, 2016; resubmitted on July 7, 2016; accepted on September 1, 2016

STUDY QUESTION: Is sexual dysfunction associated with severity of semen quality impairment in men with couple infertility?

SUMMARY ANSWER: In males of infertile couples the prevalence of erectile dysfunction (ED) increases as a function of semen quality impairment severity.

WHAT IS KNOWN ALREADY: Infertile men are at a higher risk for sexual dysfunction, psychopathological and general health disorders. However, it has never been systematically investigated if these problems are associated with severity of semen quality impairment.

STUDY DESIGN, SIZE, DURATION: Cross-sectional analysis of a first-time evaluation of 448 males of infertile couples attending an outpatient clinic from September 2010 to November 2015. In addition, 74 age-matched healthy, fertile men from an ultrasound study on male fertility were studied for comparison.

PARTICIPANTS/MATERIALS, SETTING, METHODS: All subjects underwent a complete physical, biochemical, scrotal and flaccid penile colour-Doppler ultrasound evaluation and semen analysis. Patients had already undergone at least one semen analysis; therefore, the majority were aware of their sperm quality before taking part in the study. Validated tools, such as the International Index of Sexual FunctionI5 (IIEF-I5), Premature Ejaculation Diagnostic Tool (PEDT), Middlesex Hospital Questionnaire (MHQ), National Institutes of HealthChronic Prostatitis Symptom Index (NIH-CPSI), International Prostate Symptom Score and Chronic Disease Score (CDS), were used to evaluate, respectively, sexual dysfunction, premature ejaculation (PE), psychopathological traits, prostatitis-like symptoms, lower urinary tract symptoms and general health status.

MAIN RESULTS AND THE ROLE OF CHANCE: Among men with couple infertility, 96 showed azoospermia (Group \#I), 245 at least one sperm abnormality (Group \#2) and 107 normozoospermia (Group \#3). Fertile men were considered as a control group (Group \#4). After adjusting for age, we observed a higher prevalence of ED (IIEF-I5-erectile function domain score $<26)($ I $8.3 \%$ versus $0 \% ; P=0.006)$ and PE (PEDT score $>8)(12.9 \%$ versus $4.1 \% ; P=0.036)$ in males of infertile couples compared with fertile men. The ED prevalence increases as a function of semen quality impairment severity $(P<0.000 \mathrm{I})$, even after adjusting for confounders (age, CDS, $\mathrm{MHQ}$ and $\mathrm{NIH}-\mathrm{CPSI}$ total score), despite similar hormonal, glyco-metabolic and penile vascular status. Compared to fertile men, all three groups of males with couple infertility showed a poorer erectile function, associated with an overall psychopathological burden (MHQ total score), particularly with somatized anxiety (MHQ-S). Azoospermic men showed the worst erectile function and general health: in this group, erectile function was negatively associated not only with psychopathological disturbances (MHQ total and MHQ-S scores; $P<0.000 \mathrm{I}$ ) but also with a less healthy phenotype (higher CDS; $P=0.015$ ). In addition, azoospermic men reported higher $P E$ prevalence and lower sexual desire and orgasmic function when compared to fertile men (all $P<0.05$ ), all of which were related to psychopathological symptoms.

${ }^{\dagger} \mathrm{F}$. Lotti and G. Corona contributed equally to this article.

(c) The Author 2016. Published by Oxford University Press on behalf of the European Society of Human Reproduction and Embryology. All rights reserved.

For Permissions, please email: journals.permissions@oup.com 
LIMITATIONS, REASONS FOR CAUTION: The cross-sectional nature of the study represents its main limitation. A possible selection bias concerning the control group of healthy, fertile men recruited into an ultrasound study might have occurred. Finally, causality cannot be inferred in this type of study design and hence there should be some caution in interpreting the results.

WIDER IMPLICATIONS OF THE FINDINGS: Investigation of male sexual function, general health and psychological status in infertile couples, especially if azoospermic, is advisable, in order to improve not only reproductive but also general and sexual health.

STUDY FUNDING/COMPETING INTEREST(S): Grants were received from the Ministry of University and Scientific Research (SIR project to F.L., protocol number: RBSII4LFMQ). There are no conflicts of interest.

TRIAL REGISTRATION NUMBER: None.

Key words: sexual dysfunction / erectile dysfunction / premature ejaculation / infertile men / azoospermic men / fertile men / general health status / psychopathological disturbances

\section{Introduction}

Male infertility affects $~ 7 \%$ of all men (Krausz 20I I; Giwercman and Giwercman, 2013). Although sexual dysfunctions are rarely the cause of male infertility (Krausz, 20I I; Lotti et al., 2012), they are very frequent in the general male population of reproductive age (Corona et al., 2008, 2010a; McCabe et al., 2016).

So far, a few studies investigated erectile dysfunction (ED) and/or premature ejaculation (PE) in infertile men using validated instruments (Lotti et al., 2012; Gao et al., 2013). These studies reported a prevalence of $\sim 18 \%$ and $\sim 16 \%$ for $E D$ and PE, respectively (Lotti et al., 2012; Gao et al., 2013). Infertile patients with sexual dysfunction have a higher prevalence of mood disturbances, such as anxiety and depressive symptoms, when compared to infertile men without sexual problems or fertile subjects (Ferraresi et al., 20I3; Bechoua et al., 20I6). However, the relationship between sexual dysfunction and the degree of fertility impairment has never been investigated.

Interestingly, a decreased general health status is associated with impaired male reproductive health (Salonia et al., 2009; Ventimiglia et al., 2015; Eisenberg et al., 2015, 2016a,b). In addition, serious lifethreatening conditions such as atherosclerosis, metabolic syndrome and diabetes are associated with testosterone deficiency, which is more prevalent in subfertile males (Giwercman and Giwercman, 2013). Hence, the concept that male infertility might represent an early marker of poor general health is emerging. An early diagnosis of ED and the identification of its risk factors can provide useful information for stratifying cardiovascular risk (Dong et al., 20I I; Salonia et al., 20 I2; Yamada et al., 2012; Vlachopoulos et al., 2013; Eisenberg et al., 2016a,b).

The aim of the present study is to investigate the relationship between severity of semen quality impairment and sexual function in a cohort of males of infertile couples. In addition, the data are compared to those obtained in a healthy control group with proven fertility.

\section{Materials and methods}

\section{Patients}

We studied a consecutive series of 448 male patients (mean \pm SD age $36.8 \pm 7.9$ years) attending the outpatient clinic of the Sexual Medicine and Andrology Unit of Florence (Italy) for the first time from September 2010 to November 2015, seeking medical care for couple infertility. All patients studied routinely underwent a standard diagnostic protocol for males of infertile couples (see below) and were invited to join the study, and the resulting enrolment rate was $100 \%$. Couple infertility was defined according to the World Health Organization (WHO, 2000). Patients were divided into three groups according to their sperm characteristics: azoospermic (Group $\mathrm{\# I}$ ), subjects with at least one abnormality (value $<5^{\circ}$ centile) in sperm concentration, progressive motility or sperm morphology (Group \#2) and normozoospermic (Group \#3; all the aforementioned sperm parameters $\geq 5^{\circ}$ centile) according to WHO (20l0). In Group \#I, subjects with sonographic evidence of bilateral absence of vas deferens were considered as patients with obstructive azoospermia (OA).

As a control group (Group \#4), we evaluated 74 age-matched (mean \pm SD age $36.2 \pm 5.0$ years) healthy, fertile men from a Florence spin-off of an ultrasound study on male fertility sponsored by the European Academy of Andrology (EAA; http://www.andrologyacademy.net/ studies.aspx), defined as healthy partners of a pregnant woman in the second or third trimester of pregnancy or who fathered a child during the last year, following natural conception. In particular, 116 subjects were invited to join the study and the resulting enrolment rate was $64 \%$.

All subjects were evaluated before beginning any treatment. The data reported in this study for patients have been collected according to a 'Day Service' standard protocol for males of infertile couples, encoded by PACC L-99 (D/903/II0 Azienda Ospedaliera-Universitaria Careggi [AOUC], Florence, Italy) and approved by the Regional Health Care Service (§DGRT n.I045; n.722; n.867), as previously described (Lotti et al., 20I4a). Data reported for the healthy, fertile subjects were collected according to the EAA study protocol, approved by the Florence Ethical Committee (6 June 2013; Prot.2013/0024I24) and the AOUC (II November 2013; Prot.37896/2013, Rubrica n.60/I3). All subjects underwent the following routine procedures: medical history, physical, biochemical, scrotal and flaccid penile colour-Doppler ultrasound evaluation and semen analysis. At the time of the first assessment, virtually all patients with infertility problems were aware of their semen quality, which was systematically retested in our center. In addition, all subjects were invited to complete self-administered validated questionnaires to evaluate sexual function, prostatitis-like symptoms and psychological traits. All subjects gave their written informed consent to have their clinical records included in a dedicated database and they were aware that their data, after having been made anonymous, would be used for clinical research purposes.

\section{Physical examination and lifestyle parameters}

A complete andrological and physical examination, and self-reported data on smoking, alcohol consumption behavior and physical activity were assessed according to a previous study (Lotti et al., 20I5). 
Table I Clinical, biochemical and seminal parameters of the subjects studied.

\begin{tabular}{|c|c|c|c|c|c|}
\hline & \multicolumn{3}{|c|}{ Males of infertile couples $(n=448)$} & \multirow[t]{2}{*}{ Group $4(n=74)$} & \multirow[t]{2}{*}{$P$ value } \\
\hline & Group I $(n=96)$ & Group $2(n=245)$ & Group $3(n=107)$ & & \\
\hline \multicolumn{6}{|l|}{ Clinical and laboratory parameters } \\
\hline Age (years) & $36.1 \pm 7.8$ & $37.3 \pm 7.8$ & $36.3 \pm 8.0$ & $36.2 \pm 5.0$ & 0.421 \\
\hline Current smokers (\%) & 28.1 & 22.4 & 26.1 & 24.3 & 0.558 \\
\hline Current moderate-severe alcohol consumption ( $\geq 4$ drinks/day), (\%) & 3.8 & 4.8 & 3.0 & 1.4 & 0.570 \\
\hline Current physical activity, (\%) & 40.0 & 50.9 & 57.3 & 55.4 & 0.095 \\
\hline Systolic blood pressure $(\mathrm{mmHg})$ & $123.4 \pm 11.9$ & $124.7 \pm 14.8$ & $123.7 \pm 13.7$ & $120.8 \pm 10.5$ & 0.193 \\
\hline Diastolic blood pressure $(\mathrm{mmHg})$ & $78.1 \pm 8.4$ & $79.6 \pm 8.2$ & $78.6 \pm 8.3$ & $79.3 \pm 6.2$ & 0.414 \\
\hline Waist circumference $(\mathrm{cm})$ & $97.6 \pm 14.0$ & $95.7 \pm 12.2$ & $94.5 \pm 13.1$ & $93.3 \pm 10.1$ & 0.137 \\
\hline History of cryptorchidism (\%) & 9.8 & 3.3 & 0 & 0 & $<0.0001$ \\
\hline Mean testis volume (Prader) (ml) & $16.0 \pm 6.0$ & $19.1 \pm 4.4$ & $20.9 \pm 4.4$ & $22.1 \pm 4.0$ & $<0.0001$ \\
\hline Clinical varicocele (\%) & 28.1 & 35.7 & 36.8 & 24.7 & 0.187 \\
\hline History of genito-urinary infections (\%) & 27.6 & 27.7 & 29.6 & 18.9 & 0.415 \\
\hline $\mathrm{LH}(\mathrm{IU} / \mathrm{I})$ & $3.94[2.85-6.62]$ & $3.90[2.86-5.40]$ & $3.08[2.20-4.40]$ & $3.20[2.20-4.45]$ & $<0.0001$ \\
\hline $\mathrm{FSH}(\mathrm{IU} / \mathrm{I})$ & $7.30[3.42-15.30]$ & $5.32[3.64-7.82]$ & $3.38[2.52-5.00]$ & $3.35[2.08-4.23]$ & $<0.0001$ \\
\hline Total testosterone $(\mathrm{nmol} / \mathrm{l})$ & $14.9 \pm 7.1$ & $15.4 \pm 5.6$ & $15.4 \pm 6.0$ & $16.2 \pm 5.3$ & 0.594 \\
\hline Calculated free testosterone $(\mathrm{nmol} / \mathrm{l})$ & $0.308 \pm 0.123$ & $0.319 \pm 0.103$ & $0.324 \pm 0.130$ & $0.320 \pm 0.092$ & 0.827 \\
\hline $\mathrm{SHBG}(\mathrm{nmol} / \mathrm{I})$ & $31.4 \pm 14.9$ & $31.9 \pm 13.7$ & $31.9 \pm 11.8$ & $34.4 \pm 14.4$ & 0.510 \\
\hline PSA (ng/ml) & $0.67[0.43-0.93]$ & $0.77[0.52-1.06]$ & $0.63[0.40-0.95]$ & $0.77[0.49-0.99]$ & 0.118 \\
\hline PRL (pmol/l) & $180.0[112.0-242.0]$ & I58.0 [ |17.0-231.0] & $159.0[123.8-226.5]$ & $160.0[121.0-303.0]$ & 0.991 \\
\hline $\mathrm{TSH}(\mathrm{mU} / \mathrm{L})$ & $1.65[1.15-2.40]$ & I.7। [1.17-2.35] & $1.88[1.23-2.54]$ & $1.49[1.15-2.11]$ & 0.282 \\
\hline Glycaemia (mmol/l) & $5.11 \pm 0.94$ & $5.06 \pm 0.72$ & $4.94 \pm 0.72$ & $5.00 \pm 0.61$ & 0.400 \\
\hline Insulin levels & $9.7[6.0-16.2]$ & $8.0[6.0-12.1]$ & $8.3[5.7-12.8]$ & $8.2[5.8-11.9]$ & 0.293 \\
\hline Total cholesterol (mmol/l) & $4.83 \pm 1.14$ & $5.14 \pm 0.93$ & $5.12 \pm 1.01$ & $4.99 \pm 0.90$ & 0.110 \\
\hline HDL cholesterol (mmol/l) & $1.25 \pm 0.34$ & $1.30 \pm 0.33$ & $1.25 \pm 0.31$ & $1.26 \pm 0.31$ & 0.455 \\
\hline LDL cholesterol (mmol/l) & $12.95 \pm 0.96$ & $3.18 \pm 0.81$ & $3.17 \pm 0.85$ & $3.02 \pm 0.82$ & 0.159 \\
\hline Triglycerides $(\mathrm{mmol} / \mathrm{l})$ & $1.17[0.80-1.59]$ & $1.19[0.78-1.67]$ & $1.26[0.88-1.78]$ & $1.20[0.93-1.82]$ & 0.646 \\
\hline \multicolumn{6}{|l|}{ Seminal parameters } \\
\hline Genetic abnormalities (\%) & 26 & 2.4 & 0.9 & 0 & $<0.0001$ \\
\hline Sexual abstinence (days) & $4.7 \pm 3.4$ & $4.3 \pm 1.9$ & $3.9 \pm 1.6$ & $4.3 \pm 2.5$ & 0.128 \\
\hline $\mathrm{pH}$ & $7.3 \pm 0.5$ & $7.6 \pm 0.2$ & $7.6 \pm 0.3$ & $7.7 \pm 0.2$ & $<0.0001$ \\
\hline Semen volume $(\mathrm{ml})$ & $2.5 \pm 1.8$ & $3.6 \pm 1.8$ & $3.2 \pm 1.6$ & $3.4 \pm 1.4$ & $<0.0001$ \\
\hline Sperm concentration, $\times 10^{6} / \mathrm{ml}$ & 0 & $9.0[3.0-24.8]$ & $52.0[28.0-121.0]$ & $70.0[40.5-129.1]$ & $<0.0001$ \\
\hline Sperm progressive motility (\%) & & $30.2 \pm 20.2$ & $53.9 \pm 11.4$ & $58.1 \pm 15.5$ & $<0.0001$ \\
\hline \multirow[t]{2}{*}{ Sperm normal morphology (\%) } & & $2.0[1.0-4.0]$ & $7.0[5.0-12.0]$ & $7.0[4.0-9.0]$ & $<0.0001$ \\
\hline & & & & & Continued \\
\hline
\end{tabular}




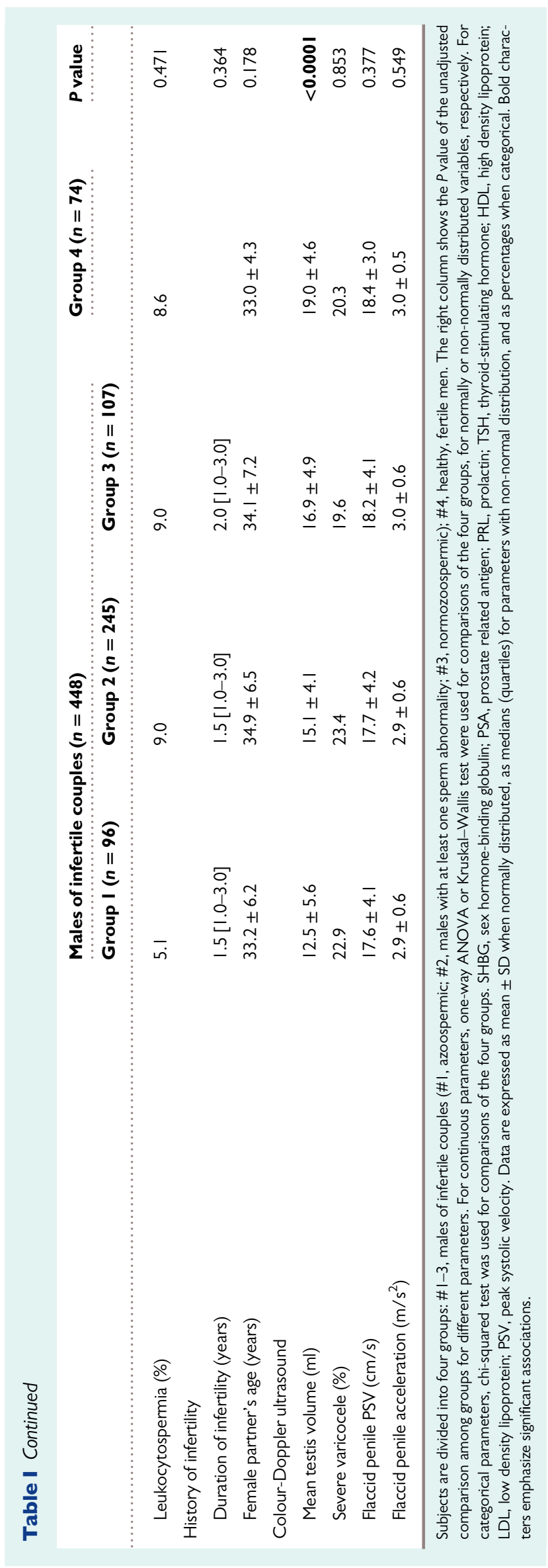

\section{Self-reported questionnaires}

Patients were invited to complete several self-reported questionnaires, including: International Index of Sexual Function-I5 (IIEF-15), Premature Ejaculation Diagnostic Tool (PEDT) National Institutes of Health-Chronic Prostatitis Symptom Index (NIH-CPSI), International Prostate Symptom Score (IPSS) and Middlesex Hospital Questionnaire (MHQ), according to previous studies (Lotti et al., 2012, 20I4b). The Chronic Disease Score (CDS), an index of concomitant morbidities, was calculated as previously described (von Korff et al., 1992).

\section{Colour-Doppler ultrasound}

All patients underwent scrotal and flaccid penile colour-Doppler ultrasound using the ultrasonographic console Hitachi H2I (Hitachi Medical System, Tokyo, Japan) and a 7.5 MHz high-frequency linear probe (L54M $6-13 \mathrm{MHz}$ ) as previously reported (Corona et al., 20 I 0b; Lotti et al., 2013; Rastrelli et al., 20।4; Lotti and Maggi, 20।5).

\section{Semen analysis and biochemical evaluation}

All patients underwent semen analysis, performed according to the $\mathrm{WHO}$ criteria (20|0).

Biochemical parameters were assessed as previously reported (Lotti et al., 2016).

\section{Data analysis}

Data were expressed as mean \pm SD when normally distributed, as medians (quartiles) for parameters with non-normal distribution, and as percentages when categorical.

For continuous parameters, one-way analysis of variance (ANOVA) or Kruskal-Wallis test were used for comparisons of more than two groups, and unpaired two-sided Student's $t$-tests or Mann-Whitney $U$ test for comparisons of two groups, for normally or non-normally distributed variables, respectively. Relative risk and $95 \% \mathrm{Cl}$ were calculated for the association of categorical parameters, and chi-squared test was used for comparisons. Subsequent multivariate analyses, adjusted for age along with other confounders when specified, were performed with analysis of covariance (ANCOVA) or binary logistic regression analysis for continuous and categorical parameters, respectively. When distribution of non-normal parameters could be normalized through logarithmic transformation, as in the case of $\mathrm{NIH}$-CPSI total score, the same tests were applied to logarithmically transformed data. A sensitivity analysis was performed with continuity corrections for variables with zero cases.

Moderator analyses were performed to clarify whether the relationship between the IIEF-I5-EFD and the CDS, the MHQ score and the $\mathrm{NIH}-\mathrm{CPSI}$ score changed according to semen quality impairment severity. A moderator is a qualitative or quantitative variable that affects the direction and/or strength of the relationship between an independent or predictor variable and a dependent or criterion variable. General linear model (GLM) was used to examine the moderating role of seminal groups on IIEF-I5-EFD and CDS, MHQ or NIH-CPSI score interaction.

Statistical analyses related to the main outcomes of the present study, i.e. ED and PE, were performed both including and excluding subjects with OA or genetic abnormalities.

All statistical analysis was performed on SPSS (Statistical Package for the Social Sciences, Chicago, IL, USA) for Windows 20.0. A $P<0.05$ was considered as significant. 
A

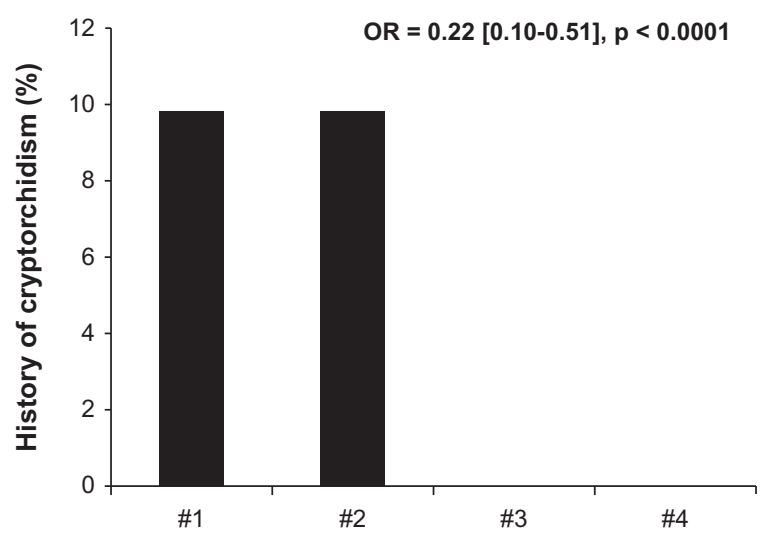

C

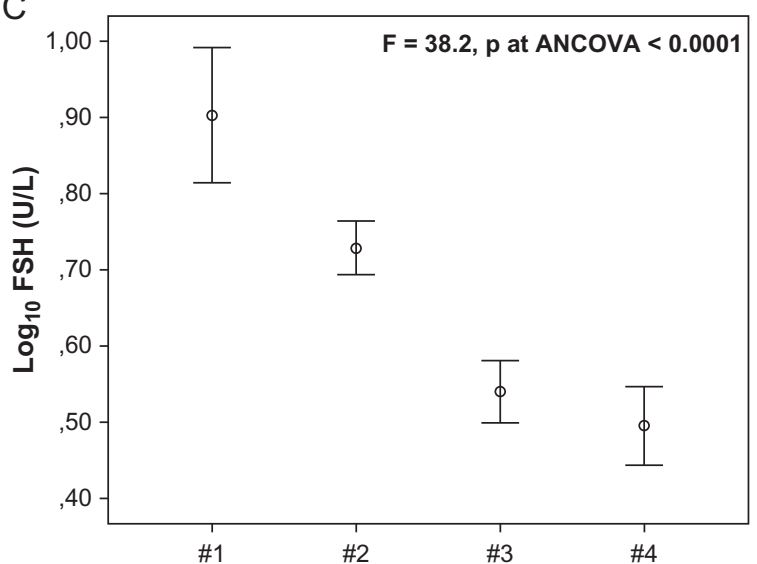

$\mathrm{B}$

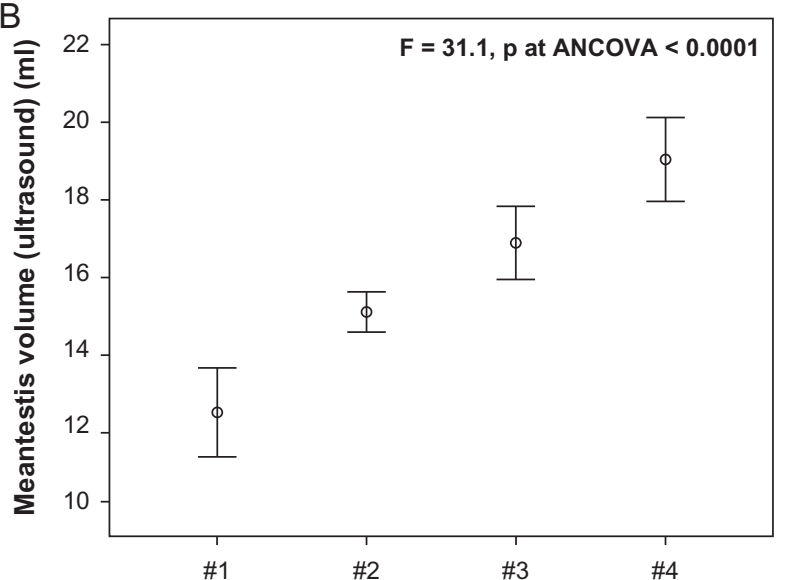

D

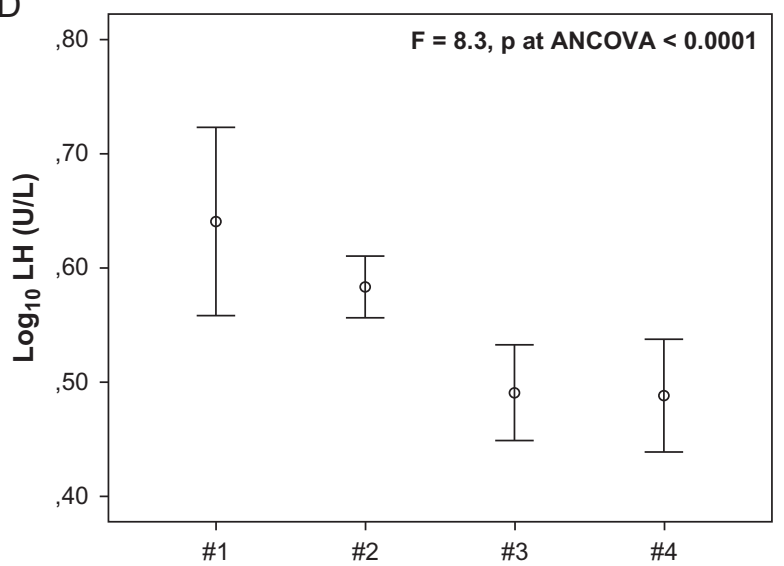

Figure I Comparison among groups of men for history of cryptorchidism, (panel A) mean testicular volume, (panel B) FSH (panel C) and LH (panel D) levels. Groups \#I-4 indicate: \#I-3, males of infertile couples (\#I, azoospermic; \#2, males with at least one sperm abnormality; \#3, normozoospermic); \#4, fertile men. The insets show the age-adjusted comparison among groups. In panels A-D, mean $\pm 95 \% \mathrm{Cl}$ of the parameters evaluated has been plotted for each group considered (\#I-4). OR: odds ratio.

\section{Results}

Among 448 consecutive males of infertile couples, 96 showed azoospermia (Group \#I), 245 at least one abnormality in sperm parameters (Group \#2) and 107 normozoospermia (Group \#3). In particular, in Group \#I we found 12 subjects with sonographic evidence of OA (bilateral absence of vas deference). In Group \#2, 28 subjects showed isolated oligozoospermia, 19 isolated asthenozoospermia, 51 isolated teratozoospermia, 18 oligo-asthenozoospermia, 31 oligo-teratozoospermia, 20 astheno-teratozoospermia and 78 oligo-astheno-teratozoospermia. A cohort of 74 age-matched healthy, fertile men was considered as a control group (Group \#4). Table I reports the clinical characteristics of the sample. No differences in the age and duration of infertility for male and female partners, as well as in male lifestyle, were observed in groups \#I-3 (Table I). Genetic abnormalities were detected in 31 men (6.9\%), including 5 karyotype abnormalities, 3 Y microdeletions and 23 vas deferens and/or seminal vesicle agenesis. Genetic abnormalities were higher in Group \#I when compared with groups \#2 and \#3 (Table I). Statistical analyses related to the main outcomes of the present study, i.e. ED and PE, were performed both including and excluding subjects with OA or genetic abnormalities (see below).

Considering Group \#2, comparing subjects with isolated or multiple sperm abnormalities, only mean testis volume (both at Prader and ultrasound evaluation) was significantly different among subgroups, being lower in oligo-astheno-teratozoospermic men and higher in subjects with isolated asthenospermia as compared to the rest of Group \#2 sample (not shown). Conversely, no differences in other clinical, biochemical, psychological and sexual parameters were observed among subgroups (not shown), hence, Group \#2 was considered as a single category for statistical analysis.

\section{Clinical and biochemical parameters}

The reported frequency of cryptorchidism, at medical history, increased as a function of semen quality impairment severity (Table I and Fig. I, panel A). Accordingly, mean testis volume, as assessed by Prader (Table I) and ultrasound evaluation (Table I and Fig. I, panel B), decreased and gonadotrophin levels (Table I and Fig. I, panels CD) increased, as a function of severity of semen quality impairment. In 

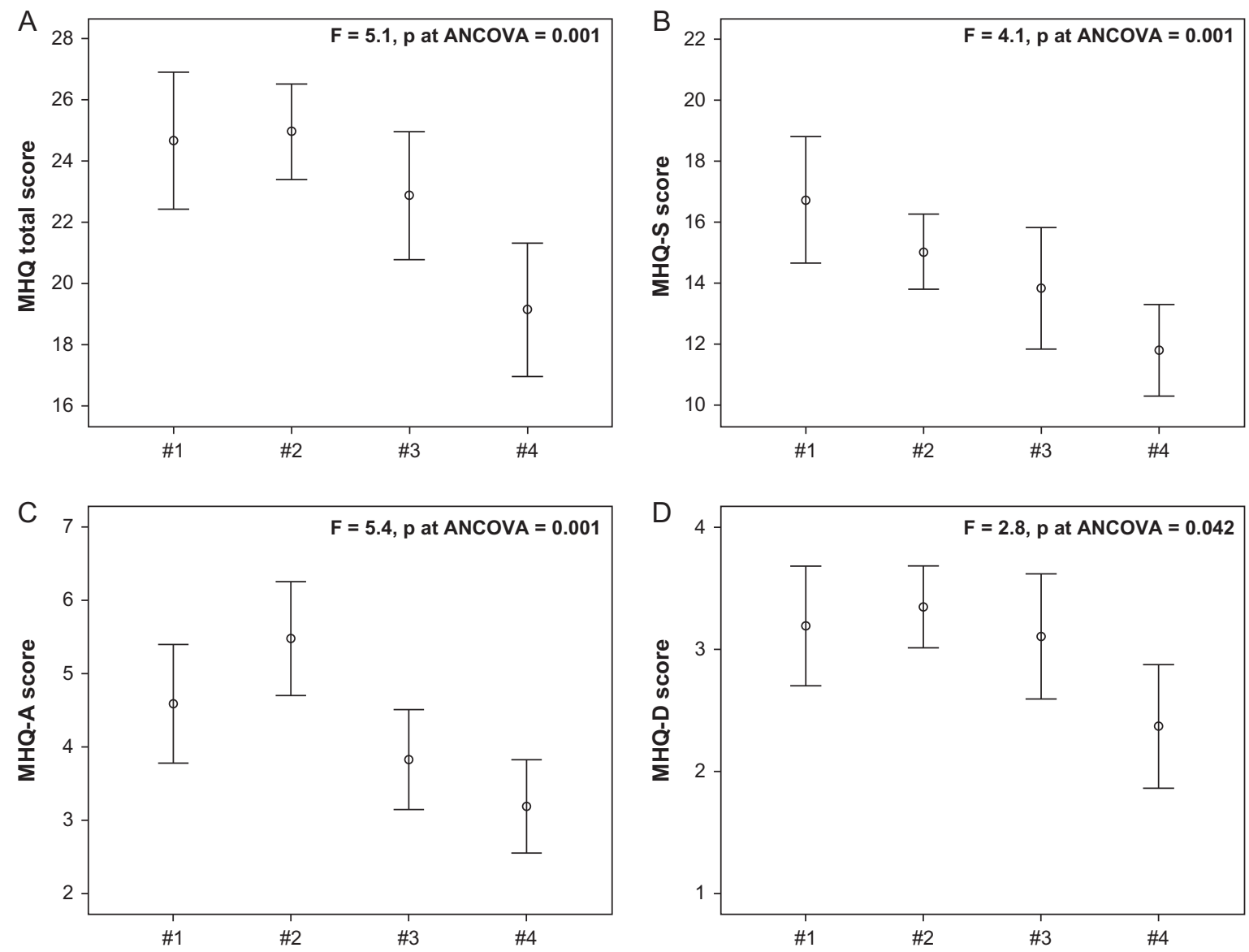

Figure 2 Comparison among groups for psychopathological traits. Comparison among groups for: overall psychopathological traits (MHQ total score) (panel A); somatized anxiety (MHQ-S) subdomain score (panel B); free-floating anxiety (MHQ-A) subdomain score (panel C); depressive symptoms (MHQ-D) subdomain score (panel D). Groups \#I-4 indicate: \#I-3, males of infertile couples (\#I, azoospermic; \#2, males with at least one sperm abnormality; \#3, normozoospermic); \#4, fertile men. The insets show the age-adjusted comparison among groups. MHQ, Middlesex Hospital Questionnaire. In panels A-D, mean $\pm 95 \% \mathrm{Cl}$ of the parameters evaluated has been plotted for each group considered (\#I-4).

particular, Group \#I showed higher prevalence of cryptorchidism, lower mean testicular volume and higher gonadotrophins (all $P<0.05$ ), compared to groups \#2, \#3 and \#4. In addition, in Group $\# \mathrm{I}$, OA subjects showed higher mean testis volume and lower gonadotrophins (all $P<0.05$ ) with respect to the rest of the azoospermic sample, without significant differences in total or calculated free testosterone levels (not shown).

No other significant differences in hormonal, glyco-metabolic and clinical parameters (including flaccid penile peak systolic velocity and acceleration) were observed among the groups (Table I).

\section{Psychological traits}

MHQ results were available for 516 men (98.8\%). Overall, MHQ total score, an index of mood and anxious psychopathology, increased as a function of severity of semen quality impairment (Fig. 2, panel A). Accordingly, somatized anxiety (MHQ-S), free-floating anxiety (MHQA) and depressive symptoms (MHQ-D) scores decreased from Group \#I to \#4 (Fig. 2, panels B-D).

\section{Prostatitis-like symptoms}

$\mathrm{NIH}-\mathrm{CPSI}$ and IPSS results were available for 516 (98.8\%) and 510 (97.7\%) men, respectively. At ANCOVA, after adjusting for age, $\mathrm{NIH}$ CPSI total or subdomains (pain and quality of life) scores were significantly lower in Group \#4 when compared to the rest of the sample (Fig. 3, panels A-C). Conversely, no difference in IPSS total score was observed (not shown).

\section{Chronic disease score}

CDS was significantly different among the groups (Fig. 3, panel D), being higher in Group \#I when compared to the rest of the sample, even after adjusting for age (Group \#I $=0.9 \pm 2.5$ versus groups \#2$4=0.3 \pm 1.1 ; F=13.5, P<0.0001)$. Accordingly, Group \#4 showed the lowest prevalence of men with CDS $>0$ when compared to the rest of the sample (Group \#4 $=6.8 \%$ versus $\# I-3=16.1 \%$, $P=0.022$ ), even after adjusting for age (odds ratio $(O R)=0.39[0.15-$ $0.99], P=0.049$ ). 

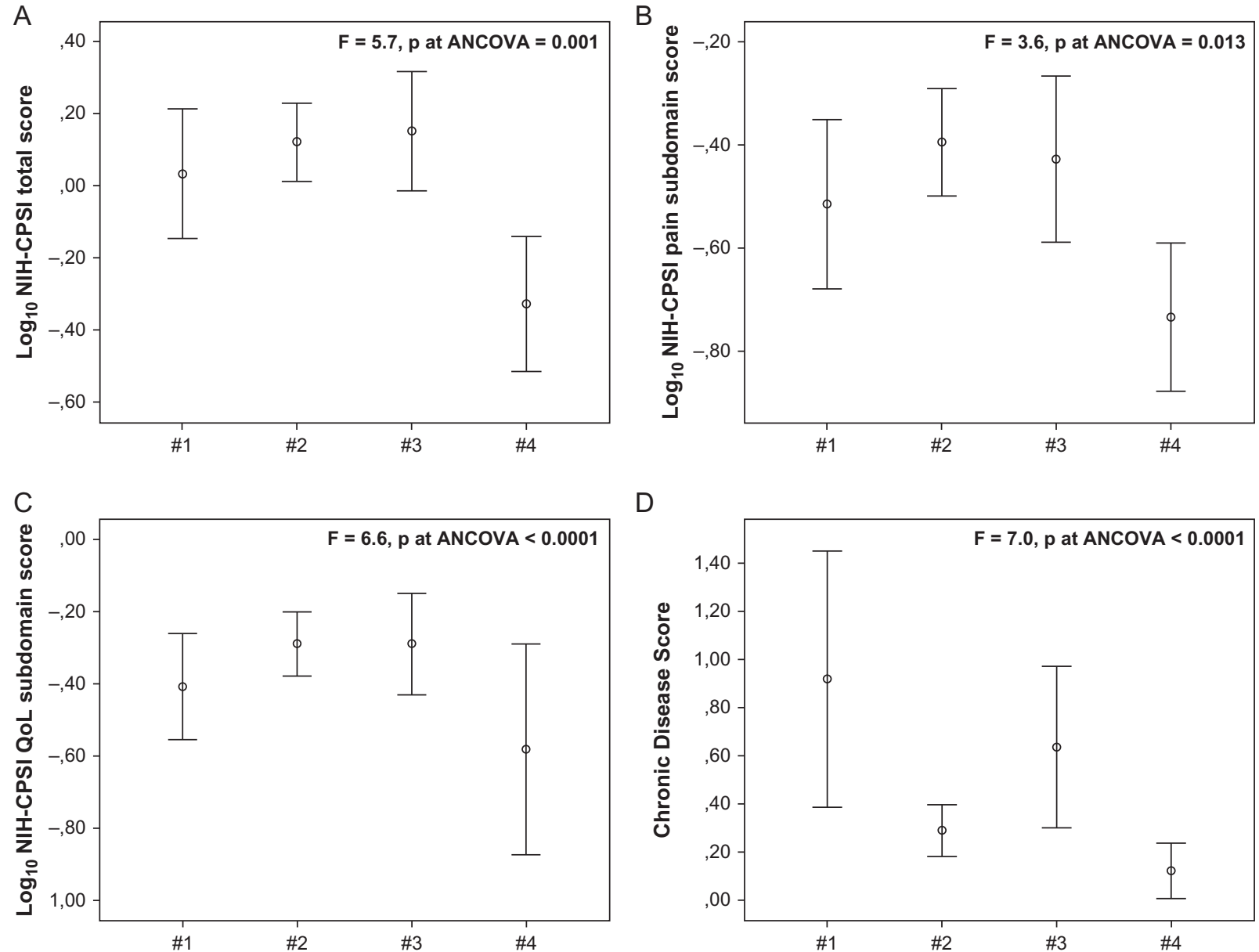

Figure 3 Comparison among groups for prostatitis-like symptoms and Chronic Disease Score. Comparison among groups for: NIH-CPSI total score (panel A); NIH-CPSI pain subdomain score (panel B); NIH-CPSI quality of life subdomain score (panel C); Chronic Disease Score (CDS) (panel D). Groups \#I-4 indicate: \#I-3, males of infertile couples (\#I, azoospermic; \#2, males with at least one sperm abnormality; \#3, normozoospermic); \#4, fertile men. The insets show the age-adjusted comparison among groups. NIH-CPSI, National Institute of Health-Chronic Prostatitis Symptom Index. In panels $\mathrm{A}-\mathrm{D}$, mean $\pm 95 \% \mathrm{Cl}$ of the parameters evaluated has been plotted for each group considered $(\# \mid-4)$.

\section{Sexual function}

IIEF- I 5 results were available for all the subjects studied. Among males of infertile couples, 82 (I8.3\%) reported ED (IIEF-I5-EFD score <26). In particular, 53 patients ( $11.8 \%$ ) had mild, 16 (3.6\%) mild to moderate, $8(1.8 \%)$ moderate and 5 (I.1\%) severe ED. Conversely, none of the fertile subjects had ED. After adjusting for age, the prevalence of any ED was higher in males of infertile couples compared with fertile men $(O R=0.06$ [0.0I-0.46], $P=0.006)$.

A significant difference in the prevalence of any kind of ED was observed among groups (Fig. 4, panel A). In particular, Group \#I showed the highest and Group \#4 the lowest prevalence of ED, even after adjustment for age (not shown). Similar results were observed when subjects with IIEF-I5-EFD score $<22$ were considered (OR $=0.30$ [0.17-0.56], $P<0.000$ I). Accordingly, IIEF-I5 total and EFD scores decreased as a function of semen quality impairment severity (Fig. 4, panels B-C), with EFD score being the lowest in Group \#I and highest in Group \#4 (not shown). The differences in
ED and IIEF-I5-EFD score among groups were confirmed after adjustment for age, CDS, $\mathrm{MHQ}$ and $\mathrm{NIH}-\mathrm{CPSI}$ total score $(\mathrm{OR}=0.55$ [0.39-0.77], $P<0.000 \mathrm{I}$ and $F=5.5, P=0.00 \mathrm{I}$, respectively). Similar results were observed when subjects with $\mathrm{OA}(\mathrm{OR}=0.57[0.40$ $0.8 \mathrm{I}], P=0.002$ and $F=3.87, P<0.01$, for ED prevalence and IIEFI5-EFD score, respectively) or genetic abnormalities (OR $=0.58$ [0.4I-0.84], $P=0.003$ and $F=3.69, P<0.02$, for ED prevalence and IIEF-I5-EFD score, respectively) were excluded from the analysis.

After adjusting for age, Group \#I showed lower scores in sexual desire $(7.4 \pm 1.4$ versus $7.9 \pm 1.4 ; F=4.20, P<0.05)$ and orgasmic function $(8.9 \pm 2.1$ versus $9.5 \pm 1.1 ; F=4.67, P<0.05)$ IIEF-I5 subdomains when compared to Group \#4. No differences in intercourse and overall sexual satisfaction were observed among groups (not shown).

\section{Ejaculatory function}

PEDT results were available for 519 men (99.4\%). According to PEDT score, 58 males of infertile couples (I2.9\%) reported PE: 26 (5.8\%) 

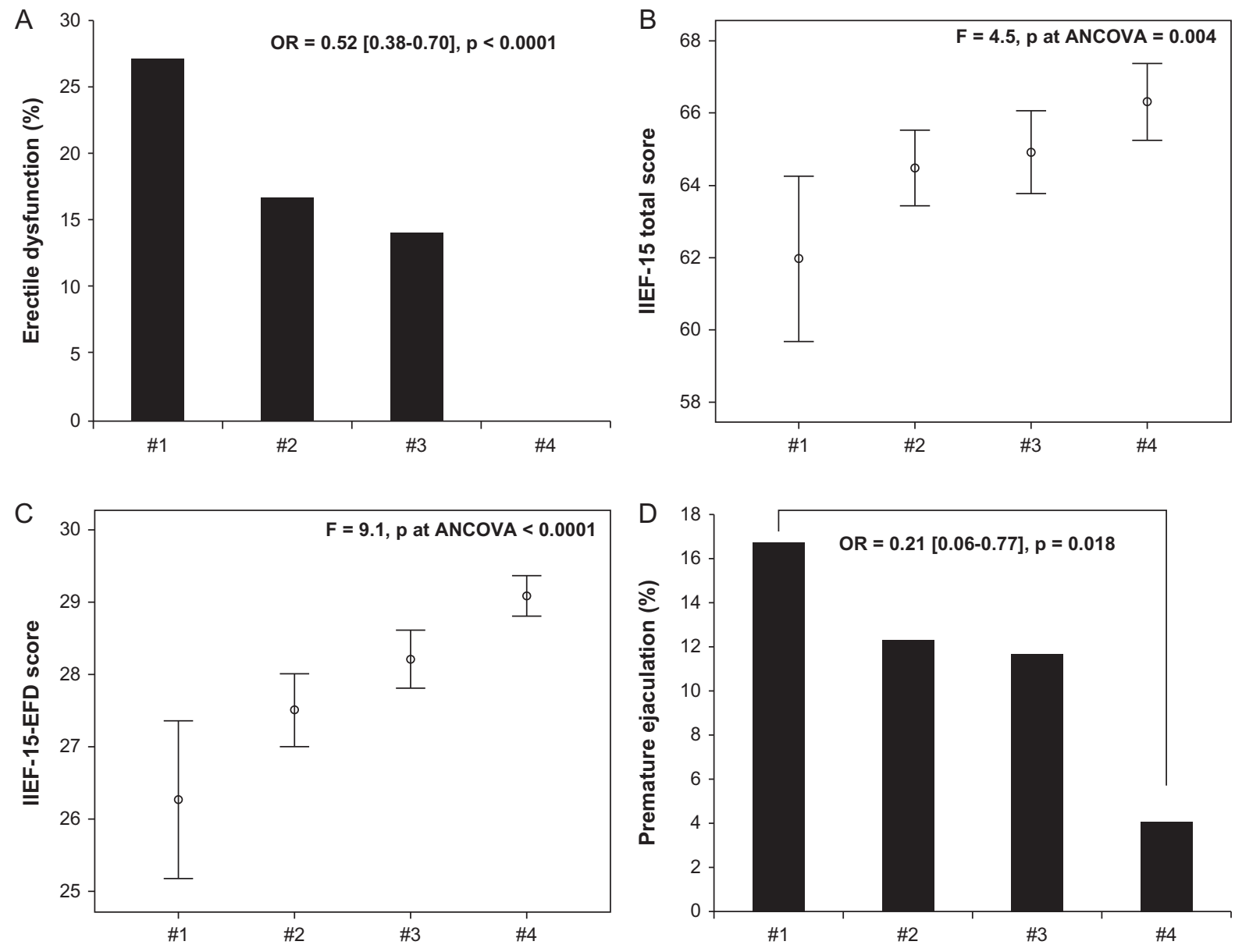

Figure 4 Comparison among groups of men for erectile dysfunction (ED) and premature ejaculation (PE). Comparison among groups for: ED prevalence (panel A); overall sexual function (IIEF-I5 total score) (panel B); erectile function (IIEF-I5-erectile function domain score) (panel C); PE prevalence (panel D). Groups \#I-4 indicate: \#I-3, males of infertile couples (\#I, azoospermic; \#2, males with at least one sperm abnormality; \#3, normozoospermic); \#4, fertile men. The insets show the age-adjusted comparison among groups. IIEF-I5, International Index of Erectile Function-I5; $E F D$, erectile function domain. In panels $A-D$, mean $\pm 95 \% \mathrm{Cl}$ of the parameters evaluated has been plotted for each group considered (\#I-4).

'probable PE' (PEDT score 9-10) and 32 (7.I\%) 'overt PE' (PEDT score $\geq \mathrm{II}$ ). Among fertile subjects, three reported PE: I (I.4\%) probable PE and 2 (2.7\%) overt PE. After adjusting for age, the prevalence of any $P E$ was lower in fertile men than in patients of infertile couples $(O R=0.28$ [0.09-0.92], $P=0.036)$. The highest prevalence of any PE was observed in Group \#I, which was significantly different from Group \#4 (Fig. 4, panel D). Similar results were observed when subjects with $O A$ or genetic abnormalities were excluded from the analysis (not shown).

\section{Moderator analysis}

We evaluated whether the relationship among IIEF-I5-EFD score and $\mathrm{CDS}, \mathrm{MHQ}$ and $\mathrm{NIH}-\mathrm{CPSI}$ scores would change as a function of severity of semen quality impairment. Accordingly we estimated the moderation effect of being in the different seminal groups on the interaction of IIEF-I5-EFD with other variables, including CDS, MHQ and $\mathrm{NIH}$ CPSI (GLM). We used the moderator analysis, which allows for the identification of subpopulations of subjects in whom a specific relationship between two variables is more likely. IIEF-I5-EFD score was negatively associated with CDS $(r=-0.158, P<0.000 \mathrm{I})$, MHQ $(r=-0.300, P<0.000 \mathrm{I})$ and $\mathrm{NIH}-\mathrm{CPSI}$ total score $(r=-0.174$, $P<0.000 \mathrm{I})$ as well as with age $(r=-0.152, P=0.00 \mathrm{I})$. The relationship between IIEF-I5-EFD score and CDS or MHQ, but not NIHCPSI, score, was differentially moderated by different seminal groups, according to the GLM (Fig. 5, panels A-D). IIEF-I 5-EFD was found to be associated with MHQ total score in groups \#I, \#2 and \#3, but not in \#4 (Fig. 5, panel A). Considering MHQ subdomains, similar associations were verified only for MHQ-S (Fig. 5, panel B). In addition, GLM revealed significant interactions between CDS and categorization into seminal groups on IIEF-I5-EFD score. IIEF-I5-EFD was found to be associated with CDS in Group \#I,but not in the other groups (Fig. 5, panel C). Conversely, the relationship between IIEF-I5-EFD and NIHCPSI total score was not moderated by different seminal groups (Fig. 5, panel D; data not shown). Similar results were observed when subjects with $O A$ were excluded from the analyses (not shown).

In addition, GLM revealed significant interactions between MHQ-D score and categorization into seminal groups (MHQ-D score * Group 
$\#$ I versus \#4: $F=4.3, P=0.015$, adjusted for age, CDS, NIH-CPSI total score, MHQ-A and MHQ-S scores) on sexual desire subdomain score, as sexual desire was found to be associated with MHQ-D score in Group \#I $(\beta=-0.314, P=0.016)$, but not in Group \#4 $(\beta=-0.186, P=0.166)$. In a similar model, GLM revealed significant interactions between MHQ-S score and categorization into seminal groups (MHQ-S score * Group \#I versus \#4: $F=7.1, P=0.01$, adjusted for age, CDS, NIH-CPSI total score, MHQ-A and MHQ-D scores) on orgasmic function subdomain score, as orgasmic function was found to be associated with MHQ-S in Group \#I $(\beta=-0.354$, $P=0.009)$, but not in Group \#4 $(\beta=-0.209, P=0.150)$.

Finally, GLM revealed a significant interaction between $\mathrm{MHQ}$ total score and categorization into seminal groups (MHQ total score * Group \#I versus \#4: $F=7.4, P=0.001$, adjusted for age, $C D S$ and $\mathrm{NIH}-\mathrm{CPSI}$ total score) on PE, as PE was found to be associated with
MHQ total score in Group \#I (OR = 1.09 [1.02-1.16], $P=0.013)$, but not in \#4 (OR = I.04 [0.94-I.15], $P=0.473)$.

Similar associations were observed when subjects with $O A$ or genetic abnormalities were excluded from the analysis (not shown).

\section{Discussion}

This is the first study investigating the association between the severity of the infertility condition and sexual dysfunction in males of infertile couples, comparing results with those of a control group of healthy, fertile subjects of similar age. We essentially found that having semen impairment exerts a negative effect not only on fathering but also on male sexuality. In particular, ED prevalence increases as a function of severity of semen quality impairment, despite similar hormonal (including testosterone), glyco-metabolic and penile vascular status of the
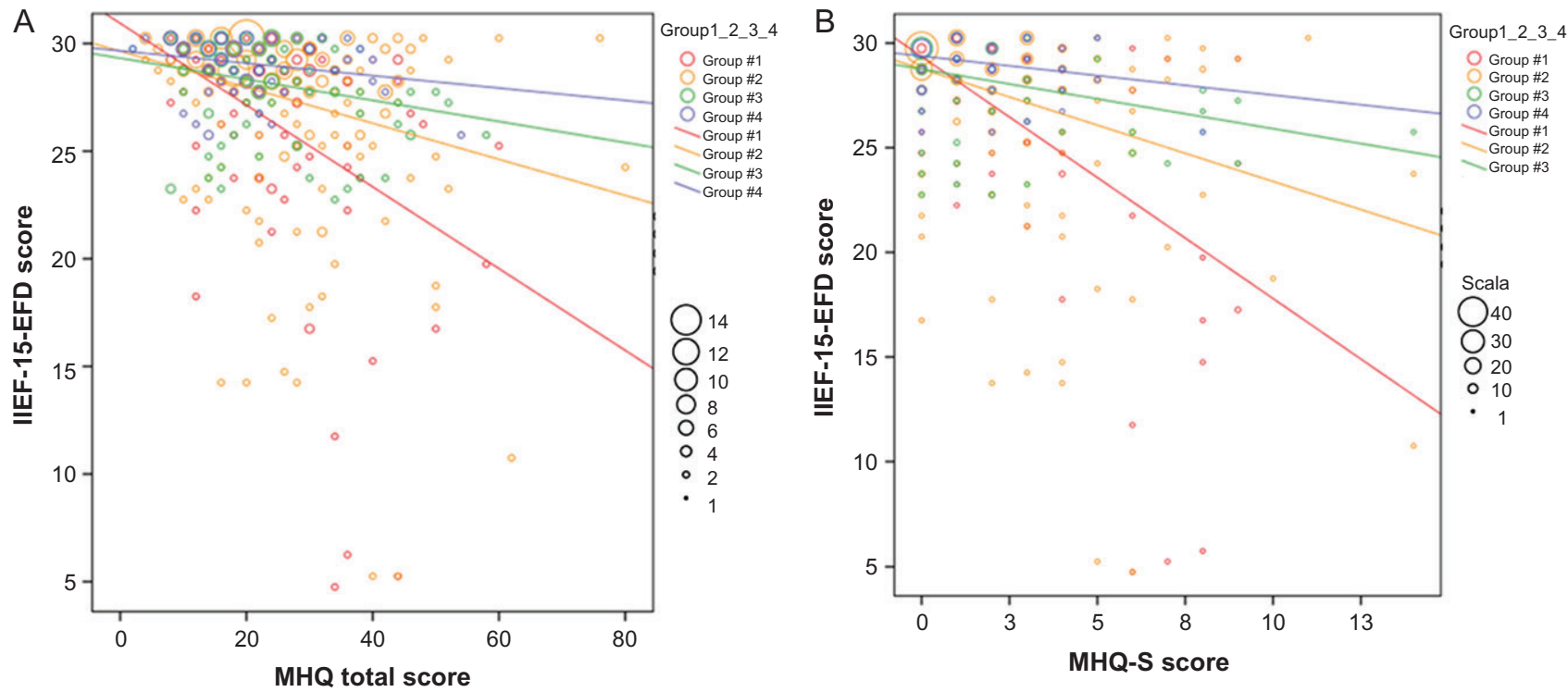

\begin{tabular}{|l|c|c|c|c|c|}
\hline \multicolumn{1}{|c|}{ Interaction } & GLM & Group \#1 & Group \#2 & Group \#3 & Group \#4 \\
\hline \#1 vs. \#4 * MHQ total score $^{\circ}$ & $\begin{array}{c}F=17.9, \\
p<0.0001\end{array}$ & $\begin{array}{c}\beta=-0.375, \\
p<0.0001\end{array}$ & - & - & $\begin{array}{c}\beta=-0.199, \\
p=0.087\end{array}$ \\
\hline \#2 vs. \#4 * MHQ total score $^{\circ}$ & $\begin{array}{r}F=13.4, \\
p<0.0001\end{array}$ & - & $\begin{array}{c}\beta=-0.249, \\
p<0.0001\end{array}$ & - & $\begin{array}{c}\beta=-0.199, \\
p=0.087\end{array}$ \\
\hline \#3 vs. \#4 * MHQ total score $^{\circ}$ & $\begin{array}{c}F=7.2, \\
p=0.001\end{array}$ & - & - & $\begin{array}{c}\beta=-0.249, \\
p=0.022\end{array}$ & $\begin{array}{c}\beta=-0.199, \\
p=0.087\end{array}$ \\
\hline
\end{tabular}

\begin{tabular}{|l|c|c|c|c|c|}
\hline Interaction & GLM & Group \#1 & Group \#2 & Group \#3 & Group \#4 \\
\hline \#1 vs. \#4 * MHQ-S total score $^{\circ 0}$ & $\begin{array}{r}F=25.5, \\
p<0.0001\end{array}$ & $\begin{array}{c}\beta=-0.511, \\
p<0.0001\end{array}$ & - & - & $\begin{array}{c}\beta=-0.234, \\
p=0.105\end{array}$ \\
\hline \#2 vs. \#4 * MHQ-S total score & $\begin{array}{r}F=12.6, \\
p<0.0001\end{array}$ & - & $\begin{array}{c}\beta=-0.337, \\
p<0.0001\end{array}$ & - & $\begin{array}{c}\beta=-0.234, \\
p=0.105\end{array}$ \\
\hline \#3 vs. \#4 * MHQ-S total score & $\begin{array}{r}F=7.3, \\
p=0.001\end{array}$ & - & & $\begin{array}{c}\beta=-0.305, \\
p=0.025\end{array}$ & $\begin{array}{c}\beta=-0.234, \\
p=0.105\end{array}$ \\
\hline
\end{tabular}

Figure 5 Associations between IIEF-I5-erectile function domain (EFD) score and psychopathological traits, CDS or prostatitis-like symptoms in groups of men with different severity of semen quality impairment, according to moderator analysis. Associations, in groups with different severity of semen quality impairment, of erectile function (IIEF-I5-EFD score) with: overall psychopathological symptoms (MHQ total score) (panel A); somatized anxiety (MHQ-S) subdomain score (panel B); CDS (panel C); NIH-CPSI total score (panel $\mathbf{D}$ ). Tables show $F$ and $p$ value of the interactions between moderator variables (comparison between groups with different severity of semen quality impairment) and MHQ total score, MHQ-S subdomain score and CDS, in a moderator analysis adjusted for confounders considering as dependent variable the IIEF-I5-EFD score. Accordingly, associations between IIEF-I5-EFD score and the aforementioned parameters in different seminal groups are shown. Because the relationship between IIEF-I5-EFD and $\mathrm{NIH}$-CPSI total score was not moderated by different seminal groups, no Table is reported in panel $\mathrm{D} .{ }^{\circ}$ adjusted for age, NIH-CPSI total score and CDS; ${ }^{\circ}$ adjusted for age, NIH-CPSI total score, CDS, MHQ-A and MHQ-D scores; ${ }^{\circ 00}$ adjusted for age, NIH-CPSI and MHQ total scores. MHQ, Middlesex Hospital Questionnaire; A, free-floating anxiety; S, somatized anxiety; D, depressive traits; IIEF-I5, International Index of Erectile FunctionI5; NIH-CPSI, National Institute of Health-Chronic Prostatitis Symptom Index; GLM, general linear model. Groups \#I-4 indicate: \#I-3, males of infertile couples (\#I, azoospermic, red circles and lines; \#2, males with at least one sperm abnormality, orange circles and lines; \#3, normozoospermic, green circles and lines); \#4, fertile men (blue circles and lines). The circle size reflects the number of observations. 

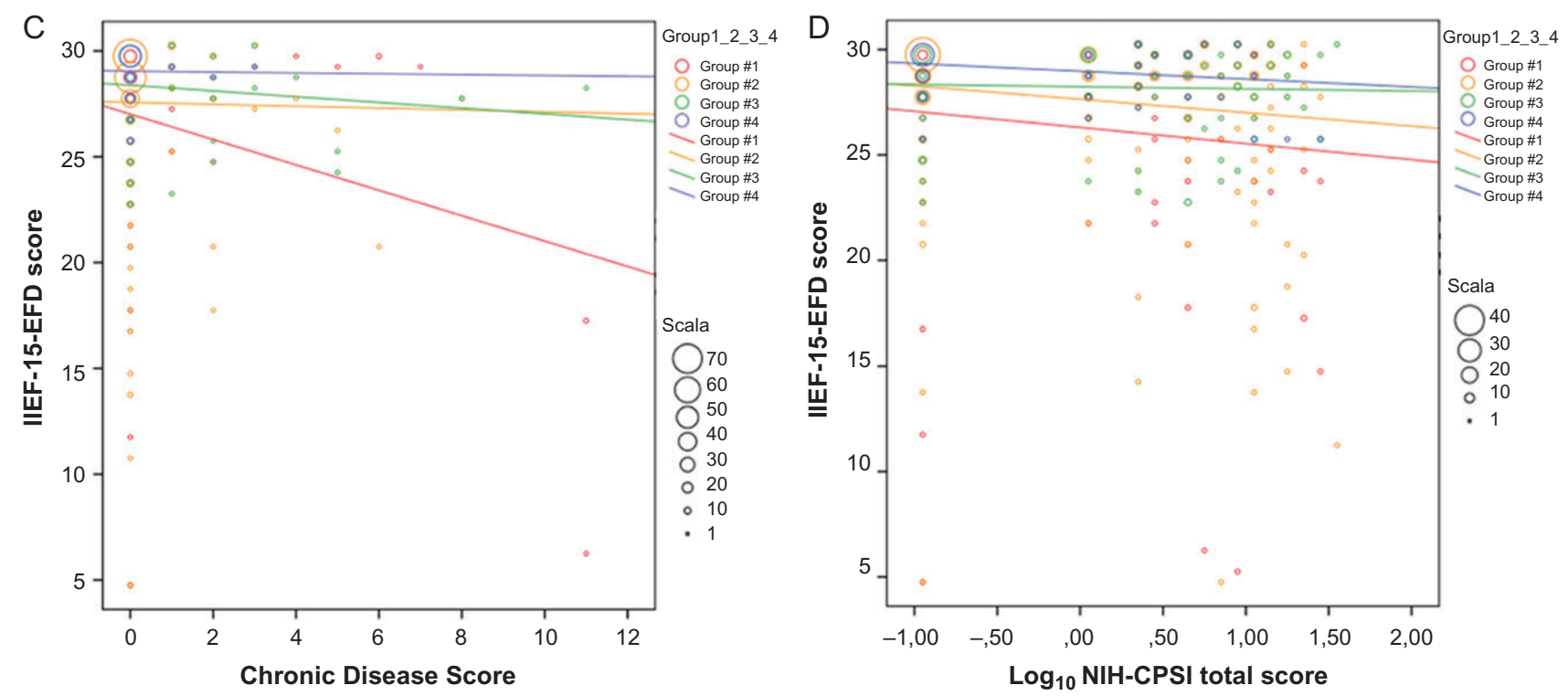

\begin{tabular}{|c|c|c|c|c|c|}
\hline Interaction & GLM & Group \#1 & Group \#2 & Group \#3 & Group \#4 \\
\hline$\# 1$ vs. $\# 2{ }^{*} \mathrm{CDS}^{\circ 00}$ & $\begin{array}{l}F=5.9, \\
p=0.003\end{array}$ & $\begin{aligned} \beta & =-0.279 \\
p & =0.015\end{aligned}$ & $\begin{array}{l}\beta=0.043, \\
P=0.514\end{array}$ & - & \\
\hline$\# 1$ vs. $\# 3^{*} \mathrm{CDS}^{\circ 00}$ & $\begin{array}{c}F=9.0, \\
p<0.0001\end{array}$ & $\begin{aligned} \beta & =-0.279 \\
p & =0.015\end{aligned}$ & - & $\begin{array}{l}\beta=-0.025 \\
p=0.811\end{array}$ & \\
\hline$\# 1$ vs. $\# 4^{*} \mathrm{CDS}^{\circ 00}$ & $\begin{array}{c}F=7.3, \\
p=0.001\end{array}$ & $\begin{aligned} \beta & =-0.279 \\
p & =0.015\end{aligned}$ & - & - & $\begin{aligned} \beta & =-0.142 \\
p & =0.215\end{aligned}$ \\
\hline
\end{tabular}

Figure 5 Continued

different groups. Compared to fertile subjects, all males with couple infertility showed a poorer erectile function closely associated with an increased psychopathological burden, particularly with somatized anxiety. Azoospermic men showed the worst sexual function and general health, with psychopathological traits and a less healthy phenotype being the most important factors underlying ED. In this group, ejaculatory latency, sexual desire and orgasmic function were reduced with respect to fertile men, and mainly associated with mood disturbances.

In our cohort, ED prevalence is in agreement with previous reports on infertile men (Lotti et al., 2012; Gao et al., 2013). Erectile function decreased in a stepwise fashion as a function of severity of semen quality impairment, although ED-related hormonal, glyco-metabolic and penile vascular parameters were not different among seminal groups. Despite this evidence, a less healthy phenotype, as assessed by CDS, was observed in infertile men, being the worst in the azoospermic group. In addition, only in the azoospermic group was CDS associated with ED. It can be speculated that the relatively young age of our cohort, with a limited duration of any underlying diseases, might explain the lack of difference observed in ED-related parameters despite a stepwise increase in CDS as a function of semen quality impairment. Accordingly, men with couple infertility have a higher rate of cancerous (Raman et al., 2005; Walsh et al., 2010; Eisenberg et al., 2013) and noncancerous (Salonia et al., 2009) conditions than agematched males of the general population or fertile men. In addition, in line with our data, a relationship between a decreased general health and sperm abnormalities has been previously reported (Eisenberg et al., 20I5; Ventimiglia et al., 20I5). Our data add new insights to this field. ED is a well-known risk factor for cardiovascular diseases in the general population (Dong et al., 20I I; Yamada et al., 2012; Vlachopoulos et al., 2013). We suggest that the presence of ED in infertile - particularly in azoospermic - men, might alert physicians to evaluate possible subclinical underlying morbidities. Whether or not ED in infertile subjects might represent an earlier marker of forthcoming cardiovascular diseases would need further studies.

As expected, azoospermic men had a higher prevalence of cryptorchidism, lower mean testicular volume and higher gonadotrophins, compared to the other groups of patients (\#2 and \#3) and controls (\#4), but testosterone levels were similar. Of note, we observed a slightly decreased testis volume and only moderately increased gonadotrophin levels with normal testosterone, while other studies reported different clinical or hormonal characteristics in azoospermic men (Wosnitzer et al., 2014; Bobjer et al., 2016). This may depend on the patient characteristics of the cohort investigated. For example, a higher prevalence of OA patients (without sonographic evidence of bilateral absence of vas deferens) or of subjects with maturation arrest might explain the different results (Wosnitzer et al., 20I4). Hormonal findings indicate a frequent condition of compensated hypogonadism in azoospermic men. It has been hypothesized that compensated male hypogonadism represents a milder form of hypogonadism potentially 
associated with neurological, psychological and cardiovascular disturbances, including alterations of bone metabolism and glycolipid profile (Giannetta et al., 20 I2; Bobjer et al., 2016). In subjects with sexual dysfunction (Corona et al., 2014) and in the general population (Tajar et al., 2010), those with compensated hypogonadism more often report mood impairment, including higher somatized anxiety and depressive symptoms, when compared to eugonadal patients. A possible explanation is that the testosterone threshold to maintain adequate mood level is lower than for other testosterone-dependent functions (Corona et al., 2014).

In our cohort, psychopathological traits increase in a stepwise fashion as a function of semen impairment. We found, for the first time, that erectile function is negatively associated with somatized anxiety, which was highest in azoospermic men. Somatized anxiety is the unconscious process by which psychological distress is expressed as physical symptoms (APA, 2013). It is well known that infertile men may develop feelings of inadequacy, guilt, depression, distress, anxiety (Ferraresi et al., 2013; Bechoua et al., 2016), low virility, low selfesteem (Owens, 1982; Gannon et al., 2004) and psychological pressure resulting from sex aimed at conception (Monga et al., 2004; Song et al., 20I5). Accordingly, the announcement of azoospermia has been described as 'the worst news ever received' (Johansson et al., 201 I). Infertility per se and related psychological problems, including anxiety, are associated with sexual dysfunction, including ED (Berger, 1980; Marci et al., 2012; Ferraresi et al., 2013; Bechoua et al., 2016).

The prevalence of PE observed in the present study is similar to what has been reported in the general population (McCabe et al., 2016). Azoospermic men showed a higher PE frequency when compared to fertile men, associated with psychopathological alterations, in line with a previous study (Gao et al., 20I3). The relationship between anxiety (Lotti et al., 2012; Zhang et al., 2013a; Gao et al., 2014) or depression (Son et al., 20II; Gao et al., 2013; Zhang et al., 2013a,b; Gao et al., 2014) and PE has been previously reported.

Azoospermic men also showed lower sexual desire and orgasmic function when compared to fertile men. Previous studies reported that hypoactive sexual desire is more prevalent in infertile men (Ramezanzadeh et al., 2006; Smith et al., 2009) than in the general population (Laumann et al., 1999; Corona et al., 2013, 2016). This has been related to the loss of spontaneity of sexual intercourse, deprived of its recreative value and subordinated to pregnancy (Cousineau and Domar, 2007). It could be speculated that azoospermic men, aware that the sexual act cannot lead to pregnancy ('firing blanks'), experience both depressive symptoms and somatic anxiety, related to decreased sexual desire and orgasmic function, respectively, along with ED.

Our study has some limitations. First, due to the cross-sectional nature of the study, no causality hypothesis can be inferred. In addition, a possible selection bias concerning the control group of healthy, fertile men might have occurred. Hence, caution is advisable in interpreting the results. Furthermore, in the CDS, some of the agents described are no longer commonly prescribed, while newer agents for treating the conditions are not listed, and chronic infections are not represented. Of note, the trend of CDS in different seminal groups is more heterogeneous than those observed for other endpoints. Hence, results derived from CDS must be considered with caution.

Another limitation is that the results obtained can be considered biased by the participants knowing their fertility status. Considering that our unit represents a second-level fertility center, patients consulting for couple infertility for the first time usually had already undergone at least one semen analysis. Hence, the majority of patients evaluated in our study were aware of their sperm quality. Even fertile subjects were aware of their fertile status, by definition. Although responses to inventories could be systematically biased by knowing their fertility status, they reflect the real emotions and feelings of subjects.

Finally, data observed in azoospermic men were confirmed after excluding subjects with genetic abnormalities from the statistical analysis. Hence, psychological symptoms and sexual dysfunctions seem to be related to the diagnosis of azoospermia, rather than a consequence of the underlying genetic diseases (Corona et al., 2010c; Towns, 20 I0; Quittner et al., 20 I6).

\section{Conclusions}

ED increases as a function of severity of semen quality impairment, independently of physical, biochemical and vascular parameters, and is associated with mood disturbances. Azoospermic men reported the worst erectile function and general health status, closely related to somatized anxiety. In addition, they also had higher PE, lower sexual desire and poorer orgasmic function, all of which were related to psychopathological symptoms. Investigation of sexual function, general health and psychological status of males of infertile couples, especially if azoospermic, is advisable, to improve not only reproductive but also general and sexual health.

\section{Acknowledgements}

We thank Erminio Filimberti, PhD, Selene Degl'Innocenti, PhD, Elisabetta Baldi, $\mathrm{PhD}$, for performing semen analysis of some of the patients included in the study.

\section{Authors' roles}

F.L., G.C. and M.M. made substantial contributions to the conception and design of the manuscript, analysis and interpretation of data and drafting the manuscript. G.C. was involved in analysis and interpretation of data. F.L., G.C. and M.M. revised the manuscript for intellectual content. F.L. and E.M. performed scrotal and penile colour-Doppler ultrasound evaluation. F.L., E.M. and M.C. were involved in acquisition and inclusion of data in a dedicated database. M.G.F. performed seminal analyses. All the authors gave final approval of the submitted version of the manuscript.

\section{Funding}

Ministry of University and Scientific Research (SIR project to F.L., protocol number: RBSII4LFMQ).

\section{Conflict of interest}

None declared. 


\section{References}

American Psychiatric Association. Diagnostic and Statistical Manual of Mental Disorders, 5th edn. Washington, DC: APA, 2013(DSM-5).

Bechoua S, Hamamah S, Scalici E. Male infertility: an obstacle to sexuality? Andrology 2016;4:395-403.

Berger DM. Couples' reactions to male infertility and donor insemination. Am J Psychiatry 1980; 137: 1047-1049.

Bobjer J, Bogefors K, Isaksson S, Leijonhufvud I, Åkesson K, Giwercman YL, Giwercman A. High prevalence of hypogonadism and associated impaired metabolic and bone mineral status in subfertile men. Clin Endocrinol (Oxf) 2016;85: 189-195.

Corona G, Fagioli G, Mannucci E, Romeo A, Rossi M, Lotti F, Sforza A, Morittu S, Chiarini V, Casella G et al. Penile doppler ultrasound in patients with erectile dysfunction (ED): role of peak systolic velocity measured in the flaccid state in predicting arteriogenic ED and silent coronary artery disease. J Sex Med 2008;5:2623-2634.

Corona G, Isidori AM, Aversa A, Burnett AL, Maggi M. Endocrinologic contro of men's sexual desire and arousal/erection. J Sex Med 20 16;13:3 I7-337.

Corona G, Lee DM, Forti G, O'Connor DB, Maggi M, O'Neill TW Pendleton N, Bartfai G, Boonen S, Casanueva FF et al. EMAS Study Group. Age-related changes in general and sexual health in middle-aged and older men: results from the European Male Ageing Study (EMAS). J Sex Med 2010a; 7: 1362-1380.

Corona G, Maseroli E, Rastrelli G, Sforza A, Forti G, Mannucci E, Maggi M. Characteristics of compensated hypogonadism in patients with sexual dysfunction. J Sex Med 20 |4; I I: | 823-1834.

Corona G, Monami M, Boddi V, Cameron-Smith M, Lotti F, de Vita G, Melani C, Balzi D, Sforza A, Forti G et al. Male sexuality and cardiovascular risk. A cohort study in patients with erectile dysfunction. J Sex Med 2010b; 7:1918-1927.

Corona G, Petrone L, Paggi F, Lotti F, Boddi V, Fisher A, Vignozzi L, Balercia G, Sforza A, Forti $G$ et al. Sexual dysfunction in subjects with Klinefelter's syndrome. Int J Androl 20 I0c;33:574-580.

Corona G, Rastrelli G, Ricca V, Jannini EA, Vignozzi L, Monami M, Sforza A, Forti G, Mannucci E, Maggi M. Risk factors associated with primary and secondary reduced libido in male patients with sexual dysfunction. J Sex Med 20 13; 10:1074-1089.

Cousineau TM, Domar AD. Psychological impact of infertility. Best Pract Res Clin Obstet Gynaecol 2007;2 I:293-308.

Dong JY, Zhang YH, Qin LQ. Erectile dysfunction and risk of cardiovascular disease: meta-analysis of prospective cohort studies. J Am Coll Cardiol 201।;58:1378-1385.

Eisenberg ML, Betts P, Herder D, Lamb DJ, Lipshultz LI. Increased risk of cancer among azoospermic men. Fertil Steril 20 I 3; 100:68I-685.

Eisenberg ML, Li S, Behr B, Pera RR, Cullen MR. Relationship between semen production and medical comorbidity. Fertil Steril 20 I 5; 103:66-7I.

Eisenberg ML, Li S, Cullen MR, Baker LC. Increased risk of incident chronic medical conditions in infertile men: analysis of United States claims data. Fertil Steril 20 I 6a; 105:629-636.

Eisenberg ML, Li S, Wise LA, Lynch CD, Nakajima S, Meyers SA, Behr B, Baker VL. Relationship between paternal somatic health and assisted reproductive technology outcomes. Fertil Steril 20 I6b. May II [Epub ahead of print].

Ferraresi SR, Lara LA, de Sá MF, Reis RM, Rosa e Silva AC. Current research on how infertility affects the sexuality of men and women. Recent Pat Endocr Metab Immune Drug Discov 20 I 3;7: 1 98-202.

Gannon K, Glover L, Abel P. Masculinity, infertility, stigma and media reports. Soc Sci Med 2004;59: I I69-1 I 75.

Gao J, Zhang X, Su P, Liu J, Shi K, Hao Z, Zhou J, Liang C. Relationship between sexual dysfunction and psychological burden in men with infertility: a large observational study in China. J Sex Med 2013; 10: 1935-1 942.
Gao J, Zhang X, Su P, Peng Z, Liu J, Xia L, Lu Z, Yang J, Tang D, Gao P et al. The impact of intravaginal ejaculatory latency time and erectile function on anxiety and depression in the four types of premature ejaculation: a large cross-sectional study in a Chinese population. J Sex Med 20|4; | I:52|-528.

Giannetta E, Gianfrilli D, Barbagallo F, Isidori AM, Lenzi A. Subclinical male hypogonadism. Best Pract Res Clin Endocrinol Metab 2012;26: 539-550.

Giwercman A, Giwercman YL. Epidemiology of male reproductive disorders. In: De Groot LJ, Beck-Peccoz P, Chrousos G, Dungan K, Grossman A, Hershman JM, Koch C, McLachlan R, New M, Rebar R et al. (eds). Endotext [Internet]. South Dartmouth (MA): MDText.com, Inc, 20I3. 2000.

Johansson M, Hellstrom AL, Berg M. Severe male infertility after failed ICSI treatment-a phenomenological study of men's experiences. Reprod Health 20I I;8: I-7.

Krausz C. Male infertility: pathogenesis and clinical diagnosis. Best Pract Res Clin Endocrinol Metab 20I I;25:27I-285.

Laumann EO, Paik A, Rosen RC. Sexual dysfunction in the United States: prevalence and predictors. JAMA 1999;28 I:537-544.

Lotti F, Corona G, Degl'Innocenti S, Filimberti E, Scognamiglio V, Vignozzi L, Forti G, Maggi M. Seminal, ultrasound and psychobiological parameters correlate with metabolic syndrome in male members of infertile couples. Andrology 20 13; 1:229-239.

Lotti F, Corona G, Mondaini N, Maseroli E, Rossi M, Filimberti E, Noci I, Forti G, Maggi M. Seminal, clinical and colour-Doppler ultrasound correlations of prostatitis-like symptoms in males of infertile couples. Andrology 2014a;2:30-4I.

Lotti F, Corona G, Rastrelli G, Forti G, Jannini EA, Maggi M. Clinical correlates of erectile dysfunction and premature ejaculation in men with couple infertility. J Sex Med 2012;9:2698-2707.

Lotti F, Corona G, Vignozzi L, Rossi M, Maseroli E, Cipriani S, Gacci M, Forti G, Maggi M. Metabolic syndrome and prostate abnormalities in male subjects of infertile couples. Asian J Androl 20 I4b; 16:295-304.

Lotti F, Corona G, Vitale P, Maseroli E, Rossi M, Fino MG, Maggi M. Current smoking is associated with lower seminal vesicles and ejaculate volume, despite higher testosterone levels, in male subjects of infertile couples. Hum Reprod 2015;30:590-602.

Lotti F, Maggi M. Ultrasound of the male genital tract in relation to male reproductive health. Hum Reprod Update 2015;21:56-83.

Lotti F, Maseroli E, Fralassi N, Degl'Innocenti S, Boni L, Baldi E, Maggi M. Is thyroid hormones evaluation of clinical value in the work-up of males of infertile couples? Hum Reprod 2016;3 I:5 I 8-529.

Marci R, Graziano A, Piva I, Lo Monte G, Soave I, Giugliano E, Mazzoni S, Capucci R, Carbonara M, Caracciolo $S$ et al. Procreative sex in infertile couples: the decay of pleasure? Health Qual Life Outcomes 2012; 10:140.

McCabe MP, Sharlip ID, Lewis R, Atalla E, Balon R, Fisher AD, Laumann E, Lee SW, Segraves RT. Risk factors for sexual dysfunction among women and men: a consensus statement from the fourth international consultation on sexual medicine 2015. J Sex Med 2016;13:153-167.

Monga M, Alexandrescu B, Katz SE, Stein M, Ganiats T. Impact of infertility on quality of life, marital adjustment, and sexual function. Urology 2004; 63:126-130.

Owens D. The desire to father: reproductive ideologies and involuntarily childless men. In: McKee L, O'Brien M (eds). The Father Figure. London, UK: Tavistock, 1982:72-86.

Quittner AL, Saez-Flores E, Barton JD. The psychological burden of cystic fibrosis. Curr Opin Pulm Med 2016;22: |87-191.

Raman JD, Nobert CF, Goldstein M. Increased incidence of testicular cancer in men presenting with infertility and abnormal semen analysis. J Urol 2005; 174: 1819-1822. 
Ramezanzadeh F, Aghssa MM, Jafarabadi M, Zayeri F. Alterations of sexual desire and satisfaction in male partners of infertile couples. Fertil Steril 2006;85:139-143.

Rastrelli G, Corona G, Lotti F, Aversa A, Bartolini M, Mancini M, Mannucci E, Maggi M. Flaccid penile acceleration as a marker of cardiovascular risk in men without classical risk factors. J Sex Med 2014; I I: 173-186.

Salonia A, Castagna G, Saccà A, Ferrari M, Capitanio U, Castiglione F, Rocchini L, Briganti A, Rigatti P, Montorsi F. Is erectile dysfunction a reliable proxy of general male health status? The case for the International Index of Erectile Function-Erectile Function domain. J Sex Med 20।2;9:2708-27I5.

Salonia A, Matloob R, Gallina A, Abdollah F, Saccà A, Briganti A, Suardi N, Colombo R, Rocchini L, Guazzoni $G$ et al. Are infertile men less healthy than fertile men? Results of a prospective casecontrol survey. Eur Urol 2009;56:1025-1031.

Smith JF, Walsh TJ, Shindel AW, Turek PJ, Wing H, Pasch L, Katz PP, Infertility Outcomes Program Project Group. Infertility Outcomes Program Project Group. Sexual, marital, and social impact of a man's perceived infertility diagnosis. J Sex Med 2009;6:2505-25I 5.

Son $\mathrm{H}$, Song SH, Lee JY, Paick JS. Relationship between premature ejaculation and depression in Korean males. J Sex Med 201।;8: 2062-2070.

Song S-H, Kim DS, Yoon TK, Hong JY, Shim SH. Sexual function and stress level of male partners of infertile couples during the fertile period. BJU 2015; II7:173-176.

Tajar A, Forti G, O’Neill TW, Lee DM, Silman AJ, Finn JD, Bartfai G, Boonen S, Casanueva FF, Giwercman A et al. EMAS Group. Characteristics of secondary, primary, and compensated hypogonadism in aging men: evidence from the European Male Ageing Study. J Clin Endocrinol Metab 2010;95:1810-1818.
Towns S. Sexuality and reproductive issues in cystic fibrosis: are we doing enough? Paediatr Respir Rev 20 10; I I:73-74.

Ventimiglia E, Capogrosso P, Boeri L, Serino A, Colicchia M, Ippolito S, Scano R, Papaleo E, Damiano R, Montorsi F et al. Infertility as a proxy of general male health: results of a cross-sectional survey. Fertil Steril 2015; 104:48-55.

Vlachopoulos CV, Terentes-Printzios DG, loakeimidis NK, Aznaouridis $\mathrm{KA}$, Stefanadis $\mathrm{Cl}$. Prediction of cardiovascular events and all-cause mortality with erectile dysfunction: a systematic review and meta-analysis of cohort studies. Circ Cardiovasc Qual Outcomes 2013;6:99-109.

Von Korff M, Wagner EH, Saunders K. A chronic disease score from automated pharmacy data. J Clin Epidemiol 1992;45: 197-203.

Walsh TJ, Schembri M, Turek PJ, Chan JM, Carroll PR, Smith JF, Eisenberg ML, Van Den Eeden SK, Croughan MS. Increased risk of high-grade prostate cancer among infertile men. Cancer 20 10; I 16:2 | 40-2 I47.

World Health Organization. WHO manual for the standardized investigation and diagnosis of the infertile couple. Cambridge: Cambridge University Press, 2000.

World Health Organization. WHO Laboratory Manual for the Examination and Processing of Human Semen, 5th edn. Geneva, Switzerland: WHO press, 2010.

Wosnitzer M, Goldstein M, Hardy MP. Review of Azoospermia. Spermatogenesis 2014;4:e282 I8. eCollection 2014. Review.

Yamada T, Hara K, Umematsu H, Suzuki R, Kadowaki T. Erectile dysfunction and cardiovascular events in diabetic men: a meta-analysis of observational studies. PLoS One 2012;7:e43673.

Zhang X, Gao J, Liu J, Xia L, Yang J, Hao Z, Zhou J, Liang C. Distribution and factors associated with four premature ejaculation syndromes in outpatients complaining of ejaculating prematurely. J Sex Med 2013a; 10:1603-161 I.

Zhang X, Gao J, Liu J, Xia L, Yang J, Hao Z, Zhou J, Liang C. Prevalence rate and risk factors of depression in outpatients with premature ejaculation. Biomed Res Int 20 I 3b;20 I 3:3 I 7468. 